\title{
The future of penile prostheses for the treatment of erectile dysfunction
}

\author{
John P. Lindsey II, Tom F. Lue, Alan W. Shindel \\ University of California, San Francisco, CA, USA \\ Correspondence to: Alan W. Shindel. University of California, San Francisco, CA, USA. Email: alan.shindel@ucsf.edu.
}

\begin{abstract}
Penile prostheses (both inflatable and malleable) are standard care in the management of erectile dysfunction (ED). Introduced over 45 years ago, modern penile implants have evolved greatly during that period of time and now represent the cutting edge in materials science and function. Despite the introduction of highly effective oral pharmacotherapy for ED, these devices have remained relevant and will almost certainly remain so for the foreseeable future. Despite their high degree of efficacy, there is always potential for further improvements in both implants themselves and the surgical techniques and processes used for their placement. In this manuscript we speculate on the future of penile implants, based in large part on the historical perspective and recent developments in the implant surgery space. We include recommendations on future technical innovations, post-operative management, and novel implant designs that may revolutionize the future management of ED.
\end{abstract}

Keywords: Erectile dysfunction (ED); penile implant; sexual dysfunction; prosthetics; material science; penile implant; sexual dysfunction; prosthetics; material science

Submitted Jun 22, 2019. Accepted for publication Aug 30, 2019.

doi: $10.21037 /$ tau.2019.09.01

View this article at: http://dx.doi.org/10.21037/tau.2019.09.01

\section{Introduction}

The use of prosthetics devices to facilitate penile erection in men with erectile dysfunction (ED) has a long and colorful history. External devices have been touted since at least the early 20th century; materials that have historically been considered for implantation include osseous materials from exogenous sources or allogenic transplants such as ribs (1). Woven acrylic and solid silicone devices were also utilized (1). These early interventions were fraught with potential for serious complications and/or poor efficacy.

The modern penile prosthesis came into being in the early 1970s with the work of F. Brantley Scott (who developed the first modern inflatable penile implant) (2) and Hernan Carrion and Michael Small (who developed a malleable device for penile insertion) (3). Over the past 45 years numerous innovations have advanced the science of penile implants; examples include devices to facilitate implant insertion (e.g., the Furlow introducer tool), lock out valves to prevent auto-inflation, kink-resistant tubing, expansile implant cylinders, easier to operate pumps, more durable implant components, and antibiotic or hydrophilic coatings to reduce risk of infection (4-6). Preassembled implants with a minimal need to splice together tubing have reduced the risk of leakage at connection points. In addition to technical improvements in the implants themselves and the tools used to insert them, surgical technique has improved in terms of (I) the methods for device insertion and reservoir placement, (II) the strategies to improve cosmesis and functional length, and the (III) techniques to reduce risk of infection. The pioneering work by the early implant surgeons has set the stage for the modern era of penile implant surgery, in which surgical management is an indispensable tool in the urologic surgeon's armamentarium of treatment options for ED. Even with the availability of highly effective oral pharmacotherapy for ED and potential future medical treatments (e.g., low-intensity shock wave therapy, stem cell or gene therapy) penile implant surgery will likely remain an important intervention.

Modern implants are marvels of sophistication with 
excellent durability and high rates of patient satisfaction (7). Nevertheless, the potential always exists for further improvement in both implants themselves and in techniques for placement. In this review, we will highlight limitations or challenges with contemporary penile implants and discuss novel directions in penile implant technology. Specifically, we will assess means to produce more durable and satisfactory prostheses, improve operative technique, and help manage perioperative infection risk.

\section{Trends in prosthesis design}

Inflatable penile prostheses (IPP) remain the standard of care in the United States, accounting for the vast majority of devices implanted. Globally, malleable devices are more often used due to cost and reliability issues. There is a general consensus that inflatable devices create a more natural flaccid look and permit a closer approximation of normal physiological erections. Interventions that reduce the price of implant materials (e.g., lower cost means to produce medical grade silicone) and/or entry of competitors into the market may lead to progressively lower costs, making inflatable devices accessible to a larger swath of the global ED population.

Aside from innovation that may reduce costs, future IPP may include more durable and/or flexible components. The realm of material's science is in constant evolution, with newer substances introduced on a regular basis. Whether these innovations can influence the design or composition of existing implants is unclear, particularly since the financial incentives for companies producing prosthetic devices may not be aligned with incremental improvements in durability.

Several ideas that have been suggested in the past include "remote controlled" penile prostheses that may be activated without the need for manual compression of a pump (8). In a more whimsical vein, some have proposed that the incorporation of elements to enhance partner pleasure may be desirable; this is most typically suggested in the form of a "vibrating" penile implant that may convey vibratory stimulation to a partner. Aside from the clear technical difficulties involved in implanting and maintaining a charge on a device that is placed inside the penis and is simultaneously powerful enough to produce external vibrations, the utility of such a device to a sexual partner remains somewhat ambiguous. In the case of female partners, vibratory stimulation is usually most pleasurable when applied to the clitoris, which may or may not come into contact with the penis during intercourse. Use of an external vibrator seems a much simpler (and safer) alternative to a vibrating penile implant.

Heat sensitive polymers that change conformation and rigidity have also been explored for the construction of penile implants. Very recently, a touchless prosthesis designed to achieve a set shape from magnetic induction was reported (9). This prosthesis, consisting of a temperaturetuned nickel titanium alloy, was implanted in both an animal model and in several cadavers in the "flaccid" state and then activated using an external magnetic inducer wand. The device was activated within 45 seconds with a small but likely clinically unimportant increase in skin temperature at the implant site. The implant was able to resist substantial buckling forces (10). Although early in development, the potential of such a device to obviate the need for pumps and hydraulic tubing may pose a substantial advantage in terms of durability and ease of operation. Long term safety, ease of activation on demand, maximal obtainable rigidity, and prevention of unwanted activation from exposure to magnetic fields (e.g., with magnetic resonance imaging) remain major issues that will need to be resolved for this form of implant.

\section{Trends in pre-operative management}

There has been some interest in the preservation/ optimization of penile length prior to radical prostatectomy via administration of routine penile traction. Data on penile traction/vacuum device placement is hampered by the absence of large multi-institutional case series and marked difficulty with patient compliance with the rigorous regimen required for apparent benefit. Nonetheless, several small series have indicated benefit (albeit modest) for men who utilize some form of "pre-habilitation" before undergoing penile implant surgery $(11,12)$.

Vacuum erection device (VED) use prior to prosthesis surgery produced a statistically significant increase in stretched penile length at surgery compared to baseline in a randomized trial (11). Men randomized to VED were required to use the device for 10-15 minutes daily for at least 1 month $(n=25)$ compared to control patients who did not use the VED ( $n=25)$. Men in the VED group realized a mean $0.8 \mathrm{~cm}$ increase in penile length $(\mathrm{P}=0.02)$ compared to a mean of $0.2 \mathrm{~cm}(\mathrm{P}=0.104)$ in the control group. Corporal dilation was described by surgeons (blinded to group allocation) as "smooth" in $100 \%$ patients in the VED group compared to just $69 \%$ of patients in the control 
group $(\mathrm{P}=0.014)$. In a similar fashion, a small case series utilized traction therapy in 10 men with instructions for 2 hours daily for 2-4 months prior to surgery. Stretched penile length showed a mean $1.5 \mathrm{~cm}$ increase over baseline at the time of surgery and a mean $0.9 \mathrm{~cm}$ increase postoperatively. Three men had no net gain. A majority (60\%) of men did report some difficulty with utilizing the device, and $40 \%$ reported pain (12).

There appears to be little downside to consideration of pre-habilitation for penile implant placement. That said, patients must be made aware that the gains appear to be somewhat modest and the "pre-habilitation" process itself can be onerous.

It is well established that surgical outcomes tend to improve as surgeon volume increases $(13,14)$. In a simplistic sense, this may relate to an increasing expertise and efficiency on the part of the surgeon, but it is equally likely that improvements in systems (e.g., operating room staff that are knowledgeable about the procedure, established treatment pathways for surgical patients, etc.) also contribute to these superior outcomes (15). Penile implants are no exception to this general rule of surgical outcomes; ergo, it may be preferable that penile prosthesis surgery not be performed by "dabblers" but rather by individuals who have had intensive training and/or extensive experience with implant surgery. A greater depth of experience and knowledge enables the implant surgeon to recognize and manage problems and potential solutions. This "center of excellence" concept is well recognized in the realm of urologic oncology, but there is no reason it cannot be applied to benign urologic surgeries such as penile implant placement.

Crucially, the enhanced ability of an experienced surgeon to recognize and manage potential problems applies in terms of both pre-operative counseling and intraoperative management. Most experienced implant surgeons have cared for patients with unreasonable or unattainable expectations. Trost et al. summarized these sorts of patients in an excellent review paper using the acronym "CURSED Penis", referring to patients with tendencies to be Compulsive/Obsessive, Unrealistic, requesting Revision, Shopping for numerous surgeons, Entitled, in Denial, or carrying a Psychiatric diagnosis (e.g., mood disorder, body dysmorphic disorder, substance abuse) (16). Standards of medical professionalism dictate that even patients with these disorders not necessarily be denied management of ED with a penile implant; however, when there is abundant evidence that the patient's perceived outcomes are likely to be poor, the surgeon is best served to defer management until such time as reasonable expectations about post-operative functional status can be set with the patient. Pre-operative expectations are a very strong predictor of post-operative outcome (17); it is essential that the patient approach penile prosthetic surgery with a reasonable idea of what a penile implant can and cannot do.

\section{Trends in operative management}

Interestingly, the measured length of penile corpora and implant length shows a trend towards slight but significant increase over time. These findings were obtained from manufacturer data so causality cannot be inferred; whether this represents (ranked of in order of decreasing likelihood based on our collective opinion) a trend towards more aggressive sizing on the part of surgeons, a trend towards greater desire for implants among patients with larger phallus size, or a shift in population penis size over a very short interval of time is unclear (18). Regardless of cause, there is obviously an upward limit on the size of implant that can be placed without major risk, so we do not foresee this as a trend that will continue indefinitely.

Increasing mean penile length also begs the question of how to size prostheses appropriately. Although clinical data are not conclusive, experimental data indicate that greater a utilization of rear tip extenders is associated with lower axial rigidity of the activated penile prosthetic, particularly in larger size implants $(19,20)$. This may relate to instability at the interface between the inflatable and non-inflatable device components and/or the relatively smaller size of the inflatable device itself when rear tip extenders are used to constitute the corporal length. The benefits of minimizing rear tip extenders must be balanced against technical challenges accessing the proximal portions of the crura and/ or burying implant tubing with the corpora itself. Optimal use of rear tip extenders in the future is likely to be driven largely by surgeon preference and patient factors.

A specific adaptation that may be easily adapted by most implant surgeons is use (or approximation) of the "no touch" technique (21). With this approach, contact with the genital skin is minimized using Ioban or similar drapes. It is also routine in this approach to change the surgical gloves and instruments that have been used for initial exposure once the field has been prepped for actual placement of the device itself. This approach is associated with infection rates of approximately $0.35 \%$ in first-time implants (21). There is little apparent downside to this approach, aside from 
some negligible expenditure in terms of time and materials; adherence to the general principles of this approach should be considered by all implant surgeons.

Placement of a retroperitoneal reservoir is one of the more stressful aspects of IPP placement. While major complications are rare, it is entry into the retropubic space at which truly disastrous intraoperative complications (e.g., bladder injury, major vascular injury, bowel injury) may occur (22). Major vascular injury is usually immediately apparent due to hemorrhage; bladder or bowel injuries may also be immediately apparent but can present in a delayed fashion with infection, urine leak, abscess/sepsis, or enterocutaneous fistula. The likelihood of any of these is increased in the setting of prior retroperitoneal surgery.

Development of means to avoid the retroperitoneal space of Retzius may mitigate these risks. In the past, implant reservoirs have been spherical so as to optimize the ratio of reservoir size to volume; this had the effect of making placement of the reservoir in superficial locations unsatisfactory in terms of cosmesis and comfort. The development of flat or clover-leaf reservoirs has facilitated the exploration of alternative sites for reservoir placement, most commonly anterior to the transversalis fascia (23). In the ideal circumstance, the reservoir may be placed via the external ring into this space and advanced superiorly into a location where subsequent herniation becomes unlikely. Cephalad placement may minimize the potential for subsequent device herniation; use of nasal specula to cannulate the external ring and long ring forceps may help facilitate this. Special tools (patterned after these existing instruments but designed with preservation of reservoir function in mind) have been developed to facilitate placement by some experts (24). This approach minimizes the potential for major surgical complications but may also increase the risk of a thin patient expressing bother from a palpable reservoir or, more seriously, experiencing reservoir herniation (24). As this approach is relatively new, longitudinal data will be required to determine whether this approach is inferior, comparable, or superior to existing means of implant placement. Ectopic placement of a reservoir posterior to the rectus muscle will also remain an option; this approach requires an extra incision for placement and for removal but obviates some of the risks of herniation and/or major visceral injury.

Phalloplasty at the time of IPP placement may be associated with greater patient satisfaction. Ventral phalloplasty, or release of the penoscrotal web, has been shown to give patients the perception of increased penile length in a study by Miranda-Sousa et al. (25). In this study 36 of 43 patients who underwent ventral phalloplasty with wedge resection of the penoscrotal web at the time of IPP reported increased penile length, while 31 of 37 patients who did not undergo phalloplasty reported penile shortening. Resection of the penoscrotal web has also been described using a "Z-plasty" (26) or "Y-V plasty" (27) technique. These various incisions for treatment of the penoscrotal web may carry more potential for complications than standard incisions, but the potential for improved cosmesis/perceived length may make them viable considerations for select cases.

Dorsal phalloplasty has also been described as a means to increases visible penile length by using permanent sutures to tack the dermis and pre-pubic fat to the pubic symphysis (13). In one study, of the 66 men who underwent dorsal phalloplasty at the time of IPP placement, only $6.1 \%$ reported penile shortening, compared to $80 \%$ of the 60 men who had IPP placement alone (13). A smaller study of 8 obese patients with problematic pre-pubic fat and refractory ED described a technique of suprapubic lipectomy followed by immediate placement of an IPP using an infrapubic approach through the large suprapubic incision. One patient in this series experienced infection, possibly related to unplanned and early removal of surgical drains, but the remainder reported satisfactory cosmetic and functional outcomes (28).

The additional surgical risks of these various surgical modifications must be weighed against the potential benefit to our patients. In the absence of additional data, we suggest that these modifications not be considered the contemporary standard of care and should be reserved for use only by experienced surgeons in the context of wellinformed patients who are likely to experience sub-optimal anatomic outcomes when using standard techniques. We do not believe that these will become standard operating procedure for the majority of IPP patients.

\section{Trends in managing infection risk in prosthetic surgery}

Infection is a devastating complication after IPP. Historically, the rate of infection for primary penile implants has been reported between $1-3 \%$ for primary implants and $10 \%$ for implants undergoing revision or replacement (29). Existing guidance on the prevention of penile implant infections (adapted from the recent International Consultation on Sexual Medicine guidelines) 
Table 1 Perioperative preparation to reduce penile implant infections

Treat urinary tract infections pre-operatively

Placement of urinary catheter to prevent urine leak onto the operative field

Administer antibiotics 1 hour prior to incision and continue for 24 hours postoperatively

Shave the patient in the operating room (not before)

Prep the skin with chlorhexidine-alcohol or equivalent solution

Utilize antibiotic coated implants

Cease tobacco use for at least 4 weeks prior to surgery

Optimize control of blood sugar in patients with diabetes

is provided in Table 1 (30).

An important and non-controversial consideration for prevention of IPP infection is administration of parenteral antibiotics prior to skin incision. Broad spectrum coverage against both Gram-positive and Gram-negative bacteria is standard in both American Urological Association and European Urology Association guidelines (31,32). However, a recent study by Gross et al. indicated that nearly a third of positive cultures obtained at the time of salvage/explant for infection revealed microorganisms resistant to standard recommended prophylaxis; examples included Candida species (11\%), anaerobes (11\%), and Staph aureus (9\%). A quarter of the positive cultures also revealed polymicrobial infections (33). The implication of this higher than expected rate of infections not responsive to traditional prophylactic antibiotics is that antibiograms may need to be constantly updated and consideration should be given to broadening antibiotic coverage, particularly if there are other risk factors for infection.

The formation of a biofilm on the surface of an IPP is believed to play a major role in the development of an infected prosthesis (34). The device may be contaminated prior to, during, or after an operation (e.g., hematogenous spread). Establishment of a biofilm occurs with the implantation of free-flowing bacterial or fungal cells (sometimes known as planktonic cells) that have the ability to establish micro-colonies through clonal expansion. Crucially, colonies can be established in as little as 16 hours, highlighting the importance of peri-operative antibiotics (35). Once colonies mature, they secrete a protective matrix comprised of polysaccharides, proteins, glycolipids, and DNA, collectively known as extrapolymeric substances (EPS). This matrix shields microbes from host immune cells while allowing the inflow of nutrients. A biofilm may be quiescent but also has the potential to disperse microbes from the colony; it is likely during this stage that an infected device becomes clinically apparent.

Biofilms are a serious challenge, as they render microbial colonies impenetrable to antibiotic therapy (35), which is the primary tool in the surgeon's armamentarium. Antibiotic coating (pre-coated into the implant itself by the manufacturer or bound by immersion of the hydrophilic implant into an antibiotic solution) appears highly effective at inhibiting the establishment of microbial colonies. This intervention has led to the current $1-3 \%$ rate of infection (29), which is lower in the context of highvolume surgeons. The rare infections that do occur in the context of antibiotic coated penile implants are typically sub-acute, presenting in a delayed fashion with chronic pain and scant drainage rather than florid purulence and sepsis. These infections may occur due to planktonic cells that are antibiotic resistant, sub-inhibitory concentrations of antibiotics, or delayed infection of the device by hematogenous spread after the antibiotic is no longer present.

A novel alternative approach to biofilm formation may be establishment of a biofilm made up of clinically indolent bacteria. The majority of clinically uninfected penile implants removed for mechanical breakdown or other reasons have evidence of biofilm formation (36-38); hence, it may not be feasible to prevent biofilm in all cases but rather to hope that biofilm which does form consists of nonpathogenic bacteria. Antimicrobial prophylaxis may thus be most important for the management of microbial species that are not prone to pathogenesis. Selection of antibiotics (for parenteral administration or for impregnation on actual devices) should be made with consideration to local antibiograms, which may vary between geographic locales.

Another intriguing innovation in the management of biofilms is the application of ultrasound-targeted 
microbubble destruction (UTMB). This intervention has been studied and shown efficacious for management of S. epidermidis biofilms in vitro and in a rabbit model (39). Administration of UTMB in conjunction with the antibiotic vancomycin has demonstrated synergy between these two means of treatment. The peptide human $\beta$-defensin 3 has also been shown to have efficacy in the destruction of Staphylococcal biofilms (40), particularly when administered in conjunction with UTMB (41). The bulk of studies to date have focused on orthopedic prostheses composed of titanium (41), but UTMB may be of interest in the management of penile prosthesis infections. Whether this approach can be applied to silastic implants utilized for penile prosthetic surgery remains unclear, but this would be a fertile line of inquiry; removal of penile prostheses is associated with dense scar tissue formation and penile length loss whereas immediate replacement carries a substantial risk of persistent infection, even in the context of copious washout for salvage $(42,43)$.

An alternative approach for the management of infected penile prosthesis has been advanced by Swords et al., who reported on the use of a cast of calcium sulfate impregnated with antimicrobials as a temporary corporal "placeholder" for use in the setting of penile implant infection. This approach was reported in two patients, one of whom returned within the prescribed time and had an uneventful replacement of a penile implant with minimal corporal scarring. The second patient did not keep to the scheduled appointments and returned 12 weeks later with reabsorption of the cast and extensive corporal scarring (44). The role of this novel approach in implant infection remains unclear; further research will be required for this to be considered standard care.

\section{Trends in post-operative management}

The opioid epidemic in America has necessitated a reassessment of how surgeons dispense narcotic pain medicine and more broadly how we manage post-operative pain. Penile implant surgery is not the most invasive of procedures, but it does involve the installation of hardware inside a very sensitive part of a man's body. Consideration must be given to means by which we may improve analgesia post-operatively.

A number of reviews have highlighted the utility of local anesthetics, administered via a dorsal penile block, pudendal nerve block, and/or by intracavernous installation (45). There is little potential downside to local anesthetics and great potential for benefit in terms of patient comfort and reduced reliance on opioids. Integration of next generation, slow-release local anesthetics has been reported and is associated with substantial reduction in post-operative opioid requirement (46). The efficacy of these local therapies may be enhanced by the integration with nonnarcotic analgesics [e.g., acetaminophen, nonsteroidal antiinflammatory drugs (NSAIDs), COX-2 inhibitors] (45).

\section{Conclusions}

Penile implants have served men well and are an essential component in the urologist's armamentarium for ED management. The opportunity to improve function and patient satisfaction should, however, be seized and best practices (in terms of perioperative management) should be integrated with the latest advances in material sciences so as to further improve our ability to care for men with ED.

\section{Acknowledgments}

Funding: None.

\section{Footnote}

Provenance and Peer Review: This article was commissioned by the Guest Editors (Larry I. Lipshultz, Alexander W. Pastuszak) for the focused issue "Contemporary Issues and Controversies in Men's Health" published in Translational Andrology and Urology. The article was sent for external peer review organized by the Guest Editors and the editorial office.

Conflicts of Interest: The focused issue "Contemporary Issues and Controversies in Men's Health" was commissioned by the editorial office without any funding or sponsorship. TFL serves as an unpaid Editorial-in-Chief of Translational Andrology and Urology. The other authors have no conflicts of interest to declare.

Ethical Statement: The authors are accountable for all aspects of the work in ensuring that questions related to the accuracy or integrity of any part of the work are appropriately investigated and resolved.

Open Access Statement: This is an Open Access article distributed in accordance with the Creative Commons Attribution-NonCommercial-NoDerivs 4.0 International 
License (CC BY-NC-ND 4.0), which permits the noncommercial replication and distribution of the article with the strict proviso that no changes or edits are made and the original work is properly cited (including links to both the formal publication through the relevant DOI and the license). See: https://creativecommons.org/licenses/by-ncnd/4.0\%.

\section{References}

1. Carrion H, Martinez D, Parker J, et al. A History of the Penile Implant to 1974. Sex Med Rev 2016;4:285-93.

2. Scott FB, Bradley WE, Timm GW. Management of erectile impotence. Use of implantable inflatable prosthesis. Urology 1973;2:80-2.

3. Small MP. Small-Carrion penile prosthesis: a report on 160 cases and review of the literature. J Urol 1978;119:365-8.

4. Mandava SH, Serefoglu EC, Freier MT, et al. Infection retardant coated inflatable penile prostheses decrease the incidence of infection: a systematic review and metaanalysis. J Urol 2012;188:1855-60.

5. Mulcahy JJ. The Development of Modern Penile Implants. Sex Med Rev 2016;4:177-89.

6. Wilson SK, Henry GD, Delk JR Jr, et al. The mentor Alpha 1 penile prosthesis with reservoir lock-out valve: effective prevention of auto-inflation with improved capability for ectopic reservoir placement. J Urol 2002;168:1475-8.

7. Wilson SK, Delk JR, Salem EA, et al. Long-term survival of inflatable penile prostheses: single surgical group experience with 2,384 first-time implants spanning two decades. J Sex Med 2007;4:1074-9.

8. Robles-Torres JI, Gomez-Guerra L, Ramos-Cuevas D, et al. PD40-04 Semiautomatic inflatable electronic penile implant prototype. J Urol 2018;199:e804-5.

9. Le B, McVary K, McKenna K, et al. A Novel Thermalactivated Shape Memory Penile Prosthesis: Comparative Mechanical Testing. Urology 2017;99:136-41.

10. Le BV, McVary KT, McKenna K, et al. Use of Magnetic Induction to Activate a "Touchless" Shape Memory Alloy Implantable Penile Prosthesis. J Sex Med 2019;16:596-601.

11. Canguven O, Talib RA, Campbell J, et al. Is the daily use of vacuum erection device for a month before penile prosthesis implantation beneficial? a randomized controlled trial. Andrology 2017;5:103-6.

12. Levine LA, Rybak J. Traction therapy for men with shortened penis prior to penile prosthesis implantation: a pilot study. J Sex Med 2011;8:2112-7.
13. Lotan Y, Roehrborn CG, McConnell JD, et al. Factors influencing the outcomes of penile prosthesis surgery at a teaching institution. Urology 2003;62:918-21.

14. Onyeji IC, Sui W, Pagano MJ, et al. Impact of Surgeon Case Volume on Reoperation Rates after Inflatable Penile Prosthesis Surgery. J Urol 2017;197:223-9.

15. Kramer AC, Sausville J, Schweber A. Practice patterns of urologists performing penile prosthesis surgery vary based on surgeon volume: results of a practice pattern survey. Int J Impot Res 2010;22:262-6.

16. Trost LW, Baum N, Hellstrom WJ. Managing the difficult penile prosthesis patient. J Sex Med 2013;10:893906; quiz 907.

17. Kramer AC, Schweber A. Patient expectations prior to coloplast titan penile prosthesis implant predicts postoperative satisfaction. J Sex Med 2010;7:2261-6.

18. Welliver C, Kottwitz M, Ahmad AE, et al. Manufacturers' data show increasing implanted cylinder sizes and measured corporal lengths in inflatable penile implants. World J Urol 2016;34:993-8.

19. Madiraju SK, Wallen JJ, Rydelek SP, et al. Biomechanical Studies of the Inflatable Penile Prosthesis: A Review. Sex Med Rev 2019;7:369-75.

20. Thirumavalavan N, Cordon BH, Gross MS, et al. Rear Tip Extenders and Penile Prosthesis Rigidity: A Laboratory Study of Coloplast Prostheses. J Sex Med 2018;15:1030-3.

21. Cohen SD, Eid JF. The "no touch" technique decreases the risk of infection after removal and replacement of malfunctioned penile prosthesis to $0.35 \%$. J Urol 2008;189:e685-6.

22. Clavell-Hernández J, Shah A, Wang R. Non-Infectious Reservoir-Related Complications During and After Penile Prosthesis Placement. Sex Med Rev 2019;7:521-9.

23. Pagliara TJ, Smith DW, Viers BR, et al. Alternative Reservoir and Balloon Placement in Complex Patients Undergoing Urologic Prostheses. Curr Urol Rep 2018;19:40.

24. Thirumavalavan N, Gross MS, Munarriz R. Techniques of Ectopic Reservoir Placement and Their Pitfalls. J Sex Med 2017;14:1451-4.

25. Miranda-Sousa A, Keating M, Moreira S, et al. Concomitant ventral phalloplasty during penile implant surgery: a novel procedure that optimizes patient satisfaction and their perception of phallic length after penile implant surgery. J Sex Med 2007;4:1494-9.

26. Alter GJ. Correction of penoscrotal web. J Sex Med 2007;4:844-7.

27. Chang SJ, Liu SP, Hsieh JT. Correcting penoscrotal 
web with the V-Y advancement technique. J Sex Med 2008;5:249-50.

28. Baumgarten AS, Beilan JA, Shah BB, et al. Suprapubic Fat Pad Excision with Simultaneous Placement of Inflatable Penile Prosthesis. J Sex Med 2019;16:333-7.

29. Darouiche RO, Bella AJ, Boone TB, et al. North American Consensus Document on Infection of Penile Prostheses. Urology 2013;82:937-42.

30. Levine LA, Becher E, Bella A, et al. Penile Prosthesis Surgery: Current Recommendations From the International Consultation on Sexual Medicine. J Sex Med 2016;13:489-518.

31. Grabe M, Bartoletti R, Bjerklund Johansen TE, et al. Guidelines on Urological Infections. 2015. Available online: https://uroweb.org/wp-content/uploads/19Urological-infections_LR2.pdf Accessed 8/17/19.

32. Wolf JS Jr, Bennett CJ, Dmochowski RR, et al. Best practice policy statement on urologic surgery antimicrobial prophylaxis. J Urol 2008;179:1379-90.

33. Gross MS, Phillips EA, Carrasquillo RJ, et al. Multicenter Investigation of the Micro-Organisms Involved in Penile Prosthesis Infection: An Analysis of the Efficacy of the AUA and EAU Guidelines for Penile Prosthesis Prophylaxis. J Sex Med 2017;14:455-63.

34. Herati AS, Lo EM. Penile prosthesis biofilm formation and emerging therapies against them. Transl Androl Urol 2018;7:960-7.

35. Welliver RC Jr, Hanerhoff BL, Henry GD, et al. Significance of biofilm for the prosthetic surgeon. Curr Urol Rep 2014;15:411.

36. Etcheverry-Giadrosich B, Torremade-Barreda J, PujolGalarza L, et al. Bacterial colonization of penile prosthesis after its withdrawal due to mechanical failure. Actas Urol Esp 2017;41:652-5.

37. Henry GD, Wilson SK, Delk JR 2nd, et al. Penile

Cite this article as: Lindsey JP 2nd, Lue TF, Shindel AW. The future of penile prostheses for the treatment of erectile dysfunction. Transl Androl Urol 2020;9(Suppl 2):S244-S251. doi: 10.21037/tau.2019.09.01 prosthesis cultures during revision surgery: a multicenter study. J Urol 2004;172:153-6.

38. Licht MR, Montague DK, Angermeier KW, et al. Cultures from genitourinary prostheses at reoperation: questioning the role of Staphylococcus epidermidis in periprosthetic infection. J Urol 1995;154:387-90.

39. He N, Hu J, Liu H, et al. Enhancement of vancomycin activity against biofilms by using ultrasound-targeted microbubble destruction. Antimicrob Agents Chemother 2011;55:5331-7.

40. Zhu C, Tan H, Cheng T, et al. Human beta-defensin 3 inhibits antibiotic-resistant Staphylococcus biofilm formation. J Surg Res 2013;183:204-13.

41. Li S, Zhu C, Fang S, et al. Ultrasound microbubbles enhance human beta-defensin 3 against biofilms. J Surg Res 2015;199:458-69.

42. Pan S, Rodriguez D, Thirumavalavan N, et al. The Use of Antiseptic Solutions in the Prevention and Management of Penile Prosthesis Infections: A Review of the Cytotoxic and Microbiological Effects of Common Irrigation Solutions. J Sex Med 2019;16:781-90.

43. Mulcahy JJ. Penile prosthesis infection: progress in prevention and treatment. Curr Urol Rep 2010;11:400-4.

44. Swords K, Martinez DR, Lockhart JL, et al. A preliminary report on the usage of an intracorporal antibiotic cast with synthetic high purity $\mathrm{CaSO} 4$ for the treatment of infected penile implant. J Sex Med 2013;10:1162-9.

45. Reinstatler L, Shee K, Gross MS. Pain Management in Penile Prosthetic Surgery: A Review of the Literature. Sex Med Rev 2018;6:162-9.

46. Cotta BH, Welliver C, Brahmamdam A, et al. Longacting liposomal bupivacaine decreases inpatient narcotic requirements in men undergoing penile prosthesis implantation. Turk J Urol 2016;42:230-4. 